\title{
The varieties of human dignity: a logical and conceptual analysis
}

\author{
Daniel P. Sulmasy
}

Published online: 27 March 2012

(C) Springer Science+Business Media B.V. 2012

\begin{abstract}
The word 'dignity' is used in a variety of ways in bioethics, and this ambiguity has led some to argue that the term must be expunged from the bioethical lexicon. Such a judgment is far too hasty, however. In this article, the various uses of the word are classified into three serviceable categories: intrinsic, attributed, and inflorescent dignity. It is then demonstrated that, logically and linguistically, the attributed and inflorescent meanings of the word presuppose the intrinsic meaning. Thus, one cannot conclude that these meanings are arbitrary and unrelated. This categorization and logical and linguistic analysis helps to unravel what seem to be contradictions in discourse about dignity and bioethics, and provides a hierarchy of meaning that has potential normative implications.
\end{abstract}

Keywords Dignity · Ethics - Bioethics - Logic · Linguistics · Philosophy

The word 'dignity' is not unambiguous. It has been observed by many scholars that the word has been used in a variety of ways in a variety of settings (Johnson 1998; Gewirth 1998; Nordenfelt 2004; Sulmasy 2007; Schroeder 2010; Jordan 2010; Cochrane 2010). Some of this scholarly analysis has been historical-philological, some has been philosophical, and some has even included empirical examinations of the ways in which certain groups of persons (particularly sick persons or health care professionals) actually use the word. This ambiguity concerning the

D. P. Sulmasy ( $\square)$

Kilbride-Clinton Professor of Medicine and Ethics, Department of Medicine and Divinity School, MacLean Center for Clinical Medical Ethics, University of Chicago, Chicago, IL, USA

e-mail: dsulmasy@uchicago.edu meaning of the word 'dignity' has led a number of observers to suggest that the word therefore has very little ethical use, especially in bioethics (Cochrane 2010; Harris 1998; Macklin 2003). If dignity can mean one thing to one person and another thing to another person than it cannot serve to resolve any ethical disputes.

This position assumes, however, that the various uses of the word 'dignity' in ethical discussions bear no relationship to one another, that each definition is subjective and stipulative, and that the word therefore ought to be expunged from bioethical discourse. The purpose of this essay is to refute that claim.

Taken to its extreme, the thesis that the word 'dignity' can mean whatever any individual wants it to mean is not sustainable. No one can make such a claim reasonably. As Wittgenstein has argued, there can be no private languages (Wittgenstein 1968). This does not mean that words are always unambiguous. Rather, my point is to suggest that the meaning of words is always a shared meaning, and that linguistic meaning is circumscribed by the rules of the language of a community of speakers. These include certain grammatical and logical constraints upon the use of a word that can be elucidated and explicated.

I will argue that the various uses of the word 'dignity' can be classified adequately and that the rules for the correct use of the word can be elucidated in just this fashion. Such an examination will show that the various uses of the word are not arbitrary, but logically and linguistically related in ways that are useful for ethical analysis.

Ordinary language analysis can be a valuable tool for ethics. Sometimes speakers of ordinary language suggest ideas that are useful for ethical reflection, or can help uncover ethical intuitions or norms that are embedded in ordinary language. At other times, ordinary language may 
require correction, as speakers have failed to take sufficient notice of how casual use of a language can sometimes obscure important ethical considerations. I take it as axiomatic that the mere fact that a word is used in a certain way does not imply that it ought to be used that way, particularly in ethical discourse. This would constitute a form of the naturalistic fallacy, illicitly deriving "an ought from an is." Careful linguistic and ethical analysis can help to avoid this pitfall. But, overall, ordinary language can provide useful insights for bioethics.

\section{The varieties of human dignity}

While a number of classifications of the variety of uses of the word 'dignity' have been offered, I have previously suggested a classification that is particularly useful for these purposes (Sulmasy 2008). Some commentators have proposed schemata involving only two categories; some many more. I propose that we consider three broad categories of usage for the word 'dignity'. Whether one surveys the historical-philological, philosophical, or empirical literatures about dignity, the classification that I have evinced seems both apt and serviceable. These categories are intrinsic, attributed, and inflorescent uses of the word 'dignity'.

Dignity is fundamentally a value term. All uses of the word refer to the worth, stature, or value of some entity. In ordinary usage, the entity at issue is a human being. To speak of human dignity, then, is to say something about the worth, stature, or value of a human being. The word can also be used to speak of the worth, stature, or value of a particular class of human beings, or the class of all human beings, as well as with respect to individuals. Generally speaking, however, the various uses of the word 'dignity' fall into one of these three categories.

By intrinsic dignity, I mean that worth, stature, or value that human beings have simply because they are human, not by virtue of any set of biological, psychological, social, economic, or political conditions, nor of the views of other persons, nor of any particular set of talents, skills, or powers. Intrinsic dignity is the value that human beings have simply by virtue of the fact that they are human. We use the word this way, for example, when we say that racism is an offense against human dignity. Used this way, 'dignity' designates a value not conferred or created by human choices, individual or collective, but a value that is prior to human attribution.

By attributed dignity, I mean that worth, stature, or value that human beings confer upon others by acts of attribution. The act of conferring this value may be accomplished individually or communally, but it always involves a choice. Attributed dignity is therefore a created value. It constitutes a conventional form of value. For instance, we attribute worth or value to those we consider to be dignitaries, those we admire, those who carry themselves in a particular way, or those who have certain talents, skills, or powers. We can even attribute worth or value to ourselves using the word this way. We use the word in this attributed way, for example, when we say that extreme poverty creates degrading and undignified living conditions.

By inflorescent dignity, I mean the way people use the word to describe the worth or value of a process that is conducive to human excellence or to describe the worth or value of a state of affairs by which an individual human being expresses human excellence. 'Inflorescent' is not a commonly used word, but it is the adjectival form of the noun 'inflorescence', which means the process of flowering or blossoming. I am employing it to convey the value that comes from flowering or flourishing. That is to say, 'dignity' is used in an inflorescent way to refer to individuals who are flourishing as human beings-living lives that are consistent with and expressive of the intrinsic dignity of the human. Dignity is thus sometimes used to refer to a state of virtue-a state of affairs by which a human being habitually acts in ways that express the intrinsic value of the human. We say, for example, that so-and-so faced a particularly trying situation with dignity. This use of the word is not purely attributed, since it depends upon some objective conception of human excellence. Nonetheless, the value to which this use of the word refers is not intrinsic, since it depends both upon actual circumstances and upon an explicit understanding of the intrinsic value of the human.

These conceptions of human dignity are not mutually exclusive. Attributed, intrinsic, and inflorescent conceptions of dignity are often at play in the same situation. Yet each has been taken as the central basis for particular moral claims in bioethics. For example, in debates about euthanasia, all three uses of the word 'dignity' have been invoked. Those opposed to euthanasia will often argue that the practice is a violation of human dignity because all persons have an equal dignity that cannot be taken away by disease or injury or the way a person appears or is treated (Sulmasy 2002). They argue that acting with the intention to end the life of such a person is thus contrary to human dignity. Such arguments invoke the intrinsic meaning of the word 'dignity'. Other commentators will argue that euthanasia ought to be legalized because human beings should not be forced to accept the indignities that often accompany terminal illness. They argue that sometimes the only way to preserve human dignity is to allow such persons to have control over the circumstances of their own deaths, or to make an exit when they have lost their dignity, for example, through the disfigurement or dependency that 
illness can wreak upon a person (Quill 1991). Such arguments invoke the attributed meaning of the word dignity. Still others will argue that euthanasia ought to be illegal because it is undignified for human beings to flee from a confrontation with their own limits or the reality of human finitude. Society ought to ratify virtues such as honesty, integrity, courage, and temperance in the face of illness, injury, and death (Kass 1974). One might also argue that human beings are intrinsically interdependent and that euthanasia instantiates an undignified failure of solidarity on the part of those charged with caring for the sick and dying. Arguments such as these evoke the inflorescent sense of the word 'dignity'. All three uses should seem familiar to anyone who has studied the euthanasia debate, whether examining historical arguments over the centuries, the current philosophical debate, or surveying the attitudes and patients and health care workers. The fact that such differing arguments and conclusions make use of the same word also argues for the need for conceptual clarification.

\section{The logical and linguistic argument}

The main thesis of this essay is not to argue that one or another of these three uses is the correct meaning for use in moral discourse. All three styles of usage of the word 'dignity' have moral meaning and moral usefulness. The central thesis of this essay is that these three uses are not merely arbitrary, such that that talk of human dignity merely requires that one should take note of which usage constitutes the language game being employed and simply play along. These uses are logically and linguistically interrelated, and one can make sense of what appear to be contradictory uses, such as competing claims that dignity is something that can be lost versus claims that it is something abidingly present. I will argue that the intrinsic sense of dignity is logically and linguistically prior to the attributed and inflorescent senses. I will further argue that this logical and linguistic priority helps to make sense of apparently contradictory uses of the word and may have moral implications that can be useful in addressing ethical problems in medicine as well as in other human endeavors.

A. All talk of attributed dignity logically and linguistically presupposes the notion of intrinsic dignity. This is the first major thesis of this essay. The argument to support it follows:

1. To say that $\mathrm{x}$ has attributed value is to say that $\mathrm{x}$ has that value by virtue of some act of individual or collective attribution. This is true by the definition of attributed dignity.

2. Artifacts are entities that have purely attributed value. The value of an artifact is assigned by its artificer(s).
This value need not be instrumental, but most often it is. Examples of artifacts with purely attributed value include tools, money, and antibiotics. ${ }^{1}$

3. Intrinsic value is the value something has by virtue of its being the kind of thing that it is.

4. Natural kinds are not artifacts, but part of the alreadyout-there-now real world (Wiggins 2001). By instantiation of A.3, each natural kind has an intrinsic value, which is the value that it has by virtue of its being the kind of thing that it is. Since natural kinds are given and not created like artifacts, the intrinsic value of a natural kind is not a result of human choice, but a value must be recognized for what it is. That is to say, the intrinsic value of a natural kind has a mind-to-world direction of fit. One is simply wrong if one does not recognize this value. The value of the natural world is not limited to the instrumental purposes or the enjoyment of human beings. The claim that all natural kinds have an intrinsic value must lie at the heart of any serious account of environmental ethics.

5. Nonetheless, natural kinds can also have humanly attributed value. Human beings can both respect and use the things of the earth. A cow, for instance, has intrinsic value. Respect for the intrinsic value of cows will dictate that there are certain ways that a cow ought not to be treated. For example, cows ought not to be subjected to unnecessary pain. But cows obviously also have attributed value. Human beings use cows instrumentally for their milk and for their meat.

6. The attributed value of a given natural kind depends, in part, upon the law-like generalizations and typical features and natural history by which that kind of thing is differentiated from the rest of reality as the kind of thing that it is (Wiggins 2001). This attributed value can be both instrumental and non-instrumental. The aesthetic beauty of a bird's song, for example, is a noninstrumental value that depends upon the bird making its kind-specific sounds. Likewise, the attributed value that a cow has for human beings as a source of dairy products depends upon its being a mammal rather than a reptile or a fish.

6.a. If the particular members of a certain natural kind are typically good for me, it is because I find some feature(s) that is (are) characteristic of that kind of thing that it is good for me. For example, a particular piece of iron is good for me or for my purposes because iron has the properties of melting at a certain

\footnotetext{
${ }^{1}$ For the purposes of this discussion we will prescind from the very interesting philosophical questions that surround the nature of aesthetic value - e.g.,-whether humanly created beauty it is purely artefactual, or whether there are objective aesthetic norms.
} 
temperature, hardening as it cools to assume a shape, ability to bear weight, etc.

6.b. If a particular member of a certain natural kind is not good for me, even though that kind of thing, as a kind, is good for me, it is because that individual lacks some kind-specific feature(s) that would typically make that kind of thing good for me. For example, if a particular cow has a pituitary abnormality that prevents it from producing milk, then, while cows might typically be good for me as a dairy farmer, this particular cow will not be good for me.

6.c. If the particular members of a certain natural kind are typically bad for me, it is because there is some kindspecific feature(s) it has that is bad for me. For example, if a particular mushroom is bad for me because it is poisonous, then (barring some sinister human modification of the mushroom) it is because that kind of mushroom is poisonous.

7. The intrinsic value of a natural kind that has attributed value for me (or for my community of attributors) is the value it has by virtue of its being the kind of thing that it is. This is true by A.4 and by the definition of intrinsic value (A.3).

8. Since the attributed value of a member of a natural kind depends upon one or more of the law-like generalizations and typical features and natural history of the kind to which it belongs, and it is by virtue of these law-like generalizations and typical features and natural history that a natural kind is the kind of thing that it is, then the attributed value of a member of a natural kind depends, at least in part, upon what gives that kind of thing its intrinsic value. The attributed value of an individual member of a natural kind thus builds upon its instrinsic value. For example, while considerations of what plants and animals are good to eat can vary from culture to culture and individual to individual, it is always still the case that the attribution of culinary value depends upon one or more characteristics of the kind of thing that the potential food item is. Consider the fact that a mushroom of a poisonous kind (the poison of which cannot be deactivated by food preparation) will not be good for anyone to eat in any culture.

9. Thus, if I attribute a value called dignity to a particular entity that is a member of a certain natural kind, then that entity must belong to a natural kind that has the value we call dignity intrinsically. This is because the attribution 'dignity' depends on some state of affairs regarding one or more kind-typical features of particular members of a certain natural kind, features that, at least in part, make them worthy of the appellation 'dignity' in any sense. Such an appellation would be based on the value that kind has, as a kind, and thus the attribution of dignity would be dependent upon a recognition of the logically prior value of intrinsic dignity.

To elaborate, if I attribute dignity to a human being, it is because I have picked that individual out as a member of the human natural kind and noted some feature that is good or useful to me or to others, and noted that those features belong to a member of a kind that has the intrinsic value we call dignity. If I suggest that a certain situation diminishes or eradicates the attributed dignity of a human being, it is because I have first picked that individual out as a member of the human natural kind, a kind that is intrinsically worthy of the appellation dignity, and noted that some feature that is typical of human beings is lacking such that the individual is no longer good or useful to me. If I suggest that a certain situation has diminished or eliminated my own attributed dignity then this is because I have first picked myself out as a member of the human natural kind, a kind that is intrinsically worthy of the appellation 'dignity', and noted that some feature that is typical of human beings is lacking, such that my self-regarding goodness or usefulness is diminished or absent.

The logic and grammar of the attributed use of the word 'dignity' thus require an implicit recognition of the intrinsic dignity of the entity. For example, one might say that urinating on a banana is odd behavior, but one does not say that it offends the dignity of the banana. Yet if someone urinates on a human being, this state of affairs is said, in an attributed sense, to be undignified. This is not because it is the urinating per se that is worthy of the attribution of indignity, but because one has first picked the individual out as a member of a natural kind worthy of the appellation 'dignity', such that urinating on this particular entity (a human being) is said to be undignified.

9.a. As a corollary, consider that one never attributes dignity to an artifact. Artifacts have no intrinsic value and thus can have no intrinsic dignity and therefore can have no attributed dignity. One does not worry about offending the dignity of a table or a positron-emission tomography scanner. Not even works of art are said to have dignity. These works may be said to reflect the inflorescent dignity of their human creators, but one does not attribute dignity to the works themselves.

Thus, all talk of attributed dignity must logically and linguistically presuppose the notion of intrinsic dignity. 
B. All talk of inflorescent dignity logically and linguistically presupposes the notion of intrinsic dignity. This is the second major thesis of this essay. The argument to support it follows:

1. To say that some entity has intrinsic value is to say that it has value by virtue of its being the kind of thing that it is. This simply follows from the definition of the word 'intrinsic' (A.3).

2. To say that an entity has intrinsic dignity is to say that it has the value called dignity by virtue of its being the kind of thing that it is. Since dignity, by definition, is a particular sort of value, this follows from B.1 by instantiation.

3. Thus, to say that some individual entity has intrinsic dignity is to say that it is a member of a particular kind that has the value called dignity.

4. While there may be other members of the class that consists of the kinds of things that properly can be said to have intrinsic dignity (viz., angels, intelligent extraterrestrials, or, arguably, porpoises), in ordinary disourse a human being is the paradigmatic example of the kind of thing that is said to have dignity by virtue of its being the kind of thing that it is.

5. If one uses the word 'dignity' in an inflorescent manner, one must know something about the kind of thing the entity in question is, since one cannot know what it means to be a flourishing example of some entity without knowing to what kind the entity belongs. This follows from the meaning of inflorescent dignity.

6. In an absolute sense, the value of being an excellent member of kind $x$ depends upon the value of the kind $\mathrm{x}$. For example, the value of being a fast or a beautiful horse is greater than the value of being a fast or a beautiful ameba.

7. Therefore, to say that a particular entity (e.g., a human being) has inflorescent dignity entails that the entity is an excellent example of a kind of thing (i.e., humankind) that has, as a kind, intrinsic dignity. In other words, one does not speak of the inflorescent dignity of an entity unless one has already picked that entity out as a member of some kind that has the value of dignity intrinsically. For example, the photoluminescence of a certain kind of bacterium or the flowering of a rosemary bush can both be beautiful, but we do not speak of flourishing bacteria or rosemary bushes as manifesting dignity. One does say, when appropriate, that a particular human being carried himself or herself with dignity, but only because the entity that is flourishing is a member of the human natural kind, a kind that has the special value we call dignity by virtue of its being the kind of thing that it is, relative to other kinds of things that there are in the universe. Thus, all talk of inflorescent dignity logically and linguistically presupposes the notion of intrinsic dignity.

\section{Some implications}

So, while it is true that the word 'dignity' can be used in a variety of ways, these various uses are not merely arbitrary and unrelated stipulations of meaning. Intrinsic, attributed, and inflorescent uses of the word can be adduced from philological, philosophical, and empirical studies. But these uses are not unrelated. First, as I have already pointed out, all dignity talk is implicitly value talk, specifying the worth, stature, or value of some entity. Value terms that have significance for our judgments of good and evil, praise and blame, and the difference between right and wrong are moral terms. The word 'dignity' is thus used as a moral term in human discourse. Second, I have established that the attributed and inflorescent uses are logically and linguistically dependent upon the intrinsic sense of the word. To attribute dignity to someone or to make note of the inflorescent dignity of a person requires that one first pick the individual out as a member of a natural kind that is intrinsically worthy of the appellation, dignity. The various uses of the word 'dignity' are thus not unrelated. Nor are they incommensurable short of an elusive, universal, intersubjective agreement that some particular feature, if expressed, confers dignity upon a person. Nor is it necessary to argue which of these three uses is "correct" in moral discourse. All are correct in a grammatical sense and their employment in ordinary language requires no further justification. Rather, it is important to be clear about which sense of the word is at play in a particular discourse in order to achieve greater precision of argument and to avoid unnecessary ethical confusion due to linguistic ambiguity.

How can this be useful in advancing bioethical debates about dignity? Take for example a qualitative empirical study of medical professionals working in hospice and palliative care that concludes that some health care professionals report that dignity is something innate in a person that cannot be lost by a patient and provides the motive for these health professionals to be in the field of end-oflife care. In the same study, however, some hospice workers argued fervently that certain medical conditions (such as loss of continence or facial deformity caused by a head and neck cancer) can rob patients of their dignity, or that the social isolation that often accompanies such circumstances can result in a very undignified state. Other subjects remarked on the ability of some of their patients to maintain a sense of calm, dignified grace and acceptance in the face of horrific suffering (Morberg Jämterud 2011). 
What sense can be made of such findings? Must one say that one set of health professionals is correct and the other incorrect in their use of the word 'dignity'? Or must one despair of the possibility of making any moral sense of the word dignity given such apparently contradictory assertions as that dignity is something that can both be lost and never be lost?

The foregoing analysis would suggest that none of the respondents in this research project are wrong and would resolve the apparent contradictions by noting that the various usages can be classified as intrinsic, attributed, and inflorescent, and that these uses are related in important ways. Those health professionals who reported that dignity was something that every patient had in equal measure and reported that recognition of this value was one of their primary motives for their involvement in caring for patients at the end of life are using the word in an intrinsic sense. They recognize in these patients the value that they have by virtue of being the kind of thing that they are-human beings. This value is radically equal among human beings and cannot be eradicated by disease and injury. Their responses to the qualitative interview can be interpreted as using the word 'dignity' in this intrinsic sense. The second group of respondents appear to be using the word in attributed sense. No one can deny that illness, injury, and death mount a relentless assault upon our convictions about the value of human beings. While we know that we are finite, we recognize something about our value as human beings that strains against the boundaries of the finite. When human beings become disfigured, dependent, irrational, or suffer great pain we rebel against this state of affairs almost instinctively, sensing that the very features that lead us to value human beings more than other kinds of things are fragile and evanescent and can be lost. In such circumstances, we will often state that the situation has become an undignified one, or that the person is in a situation that is beneath his or her dignity, or that the patient has been robbed of all her dignity. These are perfectly acceptable judgments regarding attributed dignity. The central point of this essay, however, is to note that in order to describe such a situation as one lacking in attributed dignity, one must first pick out such a patient as a member of a natural kind that has particular law-like generalizations and typical features and a natural history that confer upon all members of that kind a worth that makes them unworthy of such suffering or of being treated in such a way, for example, that they have become socially isolated. One can say coherently that they have lost a good measure of their attributed dignity only because one has first picked them out as members of a natural kind that is intrinsically worthy of the appellation 'dignity'. Thus, there is no contradiction - the word 'dignity' is simply being used in two different ways. Further, the meanings conveyed by these two usages of the word are not arbitrary because they are both importantly and critically related. Finally, when some respondents in the study say that one or another patient bore up under conditions of tremendous suffering with great dignity, they are using the word in an inflorescent sense. They mean that this individual showed great virtue and exemplified one or more human excellence, such as courage, patience, or wisdom, in a very trying situation. This judgment requires first picking the individual out as a member of a kind that is capable of such virtues. It is precisely because human beings have the kind-specific capacity for such virtues that one says that human beings are intrinsically valuable in relation to other natural kinds, possessed of a value we have called intrinsic dignity. One can thus say that a particular patient showed great inflorescent dignity in the face of a massive assault on her attributed dignity, in keeping with the intrinsic dignity of the human. All three meanings can be invoked in a single coherent sentence describing a single situation.

\section{Possible counterarguments}

One might want to argue that, for philosophical purposes, only one particular use of the word 'dignity' is correct for use in moral discourse. After all, the three-fold classification schema that I have offered is not merely a schema for classifying ordinary language, but is also a classification of philological analysis and contemporary philosophical discussions. One could argue that this is one of those cases in which ordinary language must be "corrected" by philosophy. As a general rule, however, I think it wise for philosophy to hew to ordinary language unless forced to act otherwise. All three uses of the word 'dignity' seem to have important moral meaning, and all that normative content ought to be preserved in formal philosophical analysis. Thus, even were one to demand that philosophers only employ one use of the word, one would still need to assign names to the other two meanings in order to preserve the full spectrum of moral content.

A fortiori, were one to argue that the word should be expunged from bioethical discourse or from ethical discourse in general, the loss of moral content then would be even greater than if one were to restrict its usage to one of the three meanings. One would have to justify such a purgation of moral meaning on independent grounds, and the foregoing discussion makes the ethical plausibility of such a strategy seem wanting. The strength of this essay is to suggest that there are no grounds for demanding the purgation of the word 'dignity' from bioethics on the basis that its various meanings render the word vacuous, arbitrary, or unrelated. 
One might argue that my restriction of the use of word 'dignity' to descriptions of human beings, intelligent extraterrestrials, and arguably a few other highly developed intelligent animals is too restrictive. After all, one might say, people sometimes use the word 'dignity' with respect to other creatures, such as eagles, horses, or lions. I do not deny that such use is occasionally made of the word, but I would argue that such usage is rare, solely attributive, and by analogy to the human rather than based on a recognition of equivalent intrinsic value. We do not really think lions have dignity, but we do sometimes note one or another feature that seems analogous to human virtue (such as courage) and thus metaphorically ascribe dignity to a lion. I do not think we really believe that lions have a value equivalent to that of human beings.

Relatedly, some might argue that this account is "speciesist," but I would argue that it is decidedly antispeciesist.

First, there might be those who would claim that only a morally indefensible speciesist bias could lead one to make distinctions in value among living things based on the observation of a gradation in the intrinsic value of biological natural kinds by virtue of increasing phylogenetic complexity. This claim would seem to lack common sense, however, since such a gradation in complexity among biological natural kinds culminating in the human natural kind seems obvious.

In fact, the critics do not seem to deny that there is a gradation in value among biological natural kinds that merits the making of moral distinctions. The critics who have raised the charge of speciesism, such as Singer, make a distinction themselves between species that are sentient and deserving of a place in the moral calculus, and those that are non-sentient, falling outside the moral calculus (Singer 1993). Thus, it does not seem that the charge of speciesism can be based merely upon the fact that a moral theory makes distinctions in the moral worth of biological natural kinds based upon an observation of differences in their kind-specific capacities along the continuum of phylogenetic complexity. If that were true, then my theory and Singer's theory are both equally guilty of speciesism.

Second, my theory actually recognizes an intrinsic value to all biological natural kinds and thus recognizes their moral status in a more inclusive way than does Singer. By contrast to Singer, if one bases one's theory on intrinsic value (the value each biological natural kind has by virtue of its being the kind of thing that it is) then redwood trees and the flowering plants of rainforests have an intrinsic value that commands moral respect independent of human interests or the interests of other sentient creatures. The fact that redwood trees do not have the intrinsic value called dignity by no means excludes them from moral consideration. Theories that only include sentient creatures in the moral calculus, by contrast, exclude species that are included in my theory of intrinsic value. Thus, my theory cannot be said to be speciesist on the grounds that it fails to recognize the moral worth of non-human creatures since it recognizes the intrinsic moral value of all biological natural kinds.

Third, an anti-speciesist critic might allege that all value judgments are arbitrary and made by human beings anyway and that there is no objective way to distinguish the value of one kind of living creature from another. To suggest, however, that the only value that exists in the world is by human attribution would be profoundly anthropocentric and indicative of the deepest kind of speciesism. "Man" is not "the measure of all things." By contrast, I have argued that all natural kinds have intrinsic value, independent of human attribution, whether stars, paramecia, redwood trees, tigers, or human beings. I have merely noted that there is an obvious gradation in value among the natural kinds that we know, and that the leap from other kinds of animals to human beings is the most profound of which we are aware.

Borrowing from the environmental ethics of Holmes Rolston III, I thus argue that all natural kinds have intrinsic value and can make moral claims on human beings (Rolston 1988). I merely note, in addition, that the special features of the human natural kind demand that we recognize a special degree of value to which we have assigned the name dignity. This is simply how the word is used; such use is not morally suspect but an obvious and morally instructive use of ordinary language.

Fourth, my account is anti-speciesist in the sense that any member of any natural kind that has kind-specific capacities for language, rationality, love, free will, moral agency, affect, creativity, aesthetic sensibility, humor, and an ability to grasp the finite and the infinite has dignity. If we encounter a kind of extra-terrestrial that has such kindspecific capacities, that kind of extra-terrestrial would have intrinsic dignity. ${ }^{2}$ If it can be proven that porpoises have such kind-specific capacities, then porpoises would have intrinsic dignity. This is a decidedly anti-speciesist view that, overall, affords more moral protection for other species than most moral theories.

Finally, one should note that it cannot be the case that the account is to be judged speciesist simply because the

\footnotetext{
${ }^{2}$ If the natural kind to which ET belongs has kind-specific capacities that mark it as a member of a kind that has intrinsic dignity, then there would be at least two natural kinds in the universe that had intrinsic dignity-humans and extra-terrestrials of the ET kind. That dignity would be equal among all members of each kind and between all members of the two kinds. Yet, since that dignity depends on the kind of thing each thing is, one would not say that extra-terrestrials of the ET kind have human dignity. Rather, ET would have extra-terrestrial dignity and John Doe would have human dignity.
} 
claim of superior value for human beings is being advanced by human beings. The fact that a member of a group makes a claim regarding the superiority of that group is not automatically biased. If a Chinese citizen makes the claim that China has the largest standing army of any nation in the world, that Chinese citizen would be correct and not merely offering a biased, xenophobic perspective.

One could also reject my arguments by rejecting the theory of natural kinds. The dismissal of such a powerful and increasingly influential philosophical theory, however, would itself require substantial argument. Further, while a robust notion of natural kinds has been very helpful in fully discussing the arguments in this essay, most of the arguments require only that one accept that there are different kinds of things in the world. The sort of deep skeptic who would dismiss that claim is probably not someone with whom one can engage in any sort of reasonable argument about bioethics.

\section{Conclusion}

I have argued that those who have concluded that the variety of uses of the word 'dignity' render it an ethically useless term are mistaken. These various uses can be categorized reasonably. Further, I have demonstrated that the attributed and inflorescent uses of the term depend, logically and linguistically, on the intrinsic use of the word. Understanding these classifications and relationships helps to unravel what seem to be confusions and even contradictions in discussions of dignity. The logical and linguistic priority of the intrinsic sense may have substantive ethical implications that can be explored and drawn out in future research.

\section{References}

Cochrane, A. 2010. Undignified bioethics. Bioethics 24: 234-241.

Gewirth, A. 1998. Self-fulfillment, 159-174. Princeton, NJ: Princeton University Press.

Harris, J. 1998. Cloning and human dignity. Cambridge Quarterly of Healthcare Ethics 7: 163-167.

Johnson, P.R. 1998. An analysis of "dignity". Theoretical Medicine and Bioethics 19: 337-352.

Jordan, M.C. 2010. Bioethics and "human dignity". Journal of Medicine and Philosophy 35: 180-196.

Kass, L.R. 1974. Averting one's eyes, or facing the music?: On dignity in death. Hastings Center Studies 2(2): 67-80.

Macklin, R. 2003. Dignity is a useless concept. BMJ 327(7429): $1419-1420$.

Morberg Jämterud S. 2011. Human dignity after Kant: A sustainable and relational moral idea? [abstract] 25th European Conference on Philosophy of Medicine and Health Care, August 18, Zurich, Switzerland.

Nordenfelt, L. 2004. The varieties of dignity. Health Care Analalysis 12(2): 69-81.

Quill, T. 1991. Death and dignity: A case of individualized decision making. New England Journal of Medicine 324: 691-694.

Rolston III, H. 1988. Environmental ethics. Philadelphia: Temple University Press.

Schroeder, D. 2010. Dignity: one, two, three, four, five, still counting. Cambridge Quarterly of Healthcare Ethics 19(1): 118-125.

Singer, P. 1993. Practical ethics, 2nd ed, 274-276. New York: Cambridge University Press.

Sulmasy, D.P. 2002. Death, dignity, and the theory of value. Ethical Perspectives 9: 103-118.

Sulmasy, D.P. 2007. Human dignity and human worth. In Perspectives on human dignity: A conversation, ed. N. Lickiss, and J. Malpas, 9-18. Dordrecht, Netherlands: Springer.

Sulmasy, D.P. 2008. Dignity and bioethics: History, theory, and selected applications. In Humanand dignity and bioethics, ed. E.D. Pellegrino, 469-501. Washington, DC: The President's Council on Bioethics.

Wiggins, D. 2001. Sameness and substance renewed. Cambridge, England: Cambridge University Press.

Wittgenstein L. 1968. Philosophical investigations, 244-281 (trans: Anscombe, G.E.M.), 89-97. Oxford, UK: Blackwell. 